Article

\title{
Spatiotemporal Patterns of Cultivated Land Quality Integrated with Multi-Source Remote Sensing: A Case Study of Guangzhou, China
}

\author{
Dingding Duan ${ }^{1,+}{ }^{+}$Xiao Sun ${ }^{1,+}$, Shefang Liang ${ }^{1}$, Jing Sun ${ }^{1} \mathbb{D}$, Lingling Fan ${ }^{1}$, Hao Chen ${ }^{1,2}$, Lang Xia ${ }^{1,3}$, \\ Fen Zhao ${ }^{1}$, Wanqing Yang ${ }^{1}$ and Peng Yang ${ }^{1, *}$
}

1 Key Laboratory of Agricultural Remote Sensing (AGRIRS), Ministry of Agriculture and Rural Affairs, Institute of Agricultural Resources and Regional Planning, Chinese Academy of Agricultural Sciences, Beijing 100081, China; duandingding@caas.cn (D.D.); sunxiao@caas.cn (X.S.); liangshefang@caas.cn (S.L.); sunjing@caas.cn (J.S.); fanlingling@caas.cn (L.F.); chenhao@caas.cn (H.C.); xial@nercita.org.cn (L.X.); zhaofen@caas.cn (F.Z.); yangwanqing@caas.cn (W.Y.)

2 Land Use Planning Group, Wageningen University and Research, 6700 HB Wageningen, The Netherlands

3 National Research Center of Intelligent Equipment for Agriculture, Beijing Academy of Agricultural and Forestry Sciences, Beijing 100097, China

* Correspondence: yangpeng@caas.cn; Tel.: +86-010-8210-9419

+ These authors contributed equally to this work.

\section{check for}

updates

Citation: Duan, D.; Sun, X.; Liang, S.; Sun, J.; Fan, L.; Chen, H.; Xia, L.;

Zhao, F.; Yang, W.; Yang, P. Spatiotemporal Patterns of Cultivated Land Quality Integrated with Multi-Source Remote Sensing: A Case Study of Guangzhou, China. Remote Sens. 2022, 14, 1250. https:// doi.org/10.3390/rs14051250

Academic Editors: Liang Sun, Feng Gao and Wenbin Wu

Received: 17 January 2022

Accepted: 1 March 2022

Published: 3 March 2022

Publisher's Note: MDPI stays neutral with regard to jurisdictional claims in published maps and institutional affiliations.

Copyright: (C) 2022 by the authors. Licensee MDPI, Basel, Switzerland. This article is an open access article distributed under the terms and conditions of the Creative Commons Attribution (CC BY) license (https:// creativecommons.org/licenses/by/ $4.0 /)$.

\begin{abstract}
Scientifically revealing the spatiotemporal patterns of cultivated land quality (CLQ) is crucial for increasing food production and achieving United Nations Sustainable Development Goal (SDG) 2: Zero Hunger. Although studies on the evaluation of CLQ have been conducted, an effective evaluation system that is suitable for the macro-regional scale has not yet been developed. In this study, we first defined the CLQ from four aspects: soil fertility, natural conditions, construction level, and cultivated land productivity. Then, eight indicators were selected by integrating multi-source remote sensing data to create a new CLQ evaluation system. We assessed the spatiotemporal patterns of CLQ in Guangzhou, China, from 2010 to 2018. In addition, we identified the main factors affecting the improvement of CLQ. The results showed that the CLQ continuously improved in Guangzhou from 2010 to 2018. The area of high-quality cultivated land increased by $13.7 \%$, which was mainly distributed in the traditional agricultural areas in the northern and eastern regions of Guangzhou. The areas of medium- and low-quality cultivated land decreased by $8.1 \%$ and $5.6 \%$, respectively, which were scattered throughout the whole study area. The soil fertility and high productivity capacity were the main obstacle factors that affected the improvement of CLQ. Simultaneously, the obstacle degree of stable productivity capacity gradually increased during the study period. Therefore, the targeted improvement measures could be put forward by applying biofertilizers, strengthening crop management and constructing well-facilitated farmland. The new CLQ evaluation system we proposed is particularly practical at the macro-regional scale, and the results provided targeted guidance for decision makers to improve CLQ and promote food security.
\end{abstract}

Keywords: cultivated land quality; spatiotemporal patterns; evaluation system; remote sensing; obstacle factor

\section{Introduction}

Cultivated land is the most important natural resource that plays a vital role in ensuring food security and the sustainable development of human society [1]. However, cultivated land is currently suffering from frequent natural disasters [2,3], soil nutrient loss [4,5], soil acidification, and heavy metal pollution [6,7] due to climate change and high-intensity utilization [8]. The degradation of cultivated land quality (CLQ) not only caused serious eco-environmental problems but also posed great threats to food security [9]. Therefore, how to improve CLQ and increase food production have become a research 
hotspot globally. Moreover, implementing CLQ evaluation and revealing its spatiotemporal changes can provide key information for stakeholders to understand and manage CLQ.

Research on CLQ evaluation generally includes three steps: defining the CLQ, constructing a CLQ evaluation system, and grading CLQ evaluation results [10]. The definition of CLQ is the basis of evaluation, but there is currently no unified definition for the CLQ [11,12]. In most previous studies, the soil quality or soil fertility of cultivated land received the greatest attention and has often been considered as equivalent to the CLQ [13-15]. However, cultivated land is a semi-artificial and semi-natural ecosystem, and the CLQ should be the integration of multiple qualities [16]. Therefore, some other elements of CLQ have gradually attracted attention, such as field management [15,17], ecological environment $[18,19]$, and productivity $[20,21]$.

Because of the complexity of CLQ, it should be evaluated from multiple dimensions [10]. Constructing a scientific evaluation indicator system is helpful for reflecting the comprehensive characteristics of CLQ [22]. The Chinese government has always attached great importance to the protection and improvement of CLQ [23]. Therefore, a series of CLQ indicator systems has been proposed [24-26], which emphasizes the productivity capacity and ecological environment of cultivated land. Simultaneously, many scholars have also constructed a variety of evaluation indicator systems with different functions and purposes. The evaluation indicator systems developed in these studies are mainly characterized by soil quality/fertility [27-29], natural quality/conditions [30-32], utilization conditions [12,33], productivity capacity $[15,21,34]$, ecological environment $[10,18,19]$, and economic level [12]. However, the quantification methods of these indicators in existing studies were not suitable for regional scales or cannot reflect the spatial details of CLQ.

It is still a major challenge to obtain a large number of ground-measured data to evaluate CLQ at a large regional scale [35,36]. To efficiently evaluate CLQ, remote sensing data with a wide coverage have been used to characterize some of the attributes of CLQ. For example, Liu et al. [35] and Wang et al. [37] used different vegetation indexes extracted from remote sensing images to represent the soil fertility and soil moisture of cultivated land. Askari et al. [14] and Omer et al. [38] evaluated soil quality using visible and near-infrared spectroscopy. Ma et al. [34] used gross primary productivity (GPP) based on Moderate Resolution Imaging Spectroradiometer (MODIS) data to characterize the productivity of cultivated land. However, these studies mainly used remote sensing data to characterize a single attribute of the CLQ. Few studies have comprehensively evaluated the CLQ based on remote sensing data.

In addition, the CLQ has obvious spatiotemporal heterogeneity [27]. It is crucial to reveal the spatiotemporal changes in the CLQ and to identify its main influencing factors to improve CLQ [11,39]. Qian et al. [40] revealed the spatiotemporal characteristics of the production function, ecological function, and social function of the cultivated land in Shenyang city. However, its spatial resolution was low $(10 \times 10 \mathrm{~km})$, resulting in the spatial details of CLQ being poorly displayed. Lin et al. [27] carried out a study on the spatiotemporal evaluation of CLQ at a finer spatial scale (plot scale), but the authors assumed that there was no change in the CLQ grade during the study period. At present, there is still a lack of research on the spatiotemporal evaluation of CLQ at a fine spatial scale (e.g., $30 \times 30 \mathrm{~m})$.

This study aimed to (1) construct a new CLQ evaluation system by integrating multisource remote sensing data to improve the efficiency of the spatiotemporal evaluation of the CLQ; (2) reveal the spatiotemporal patterns of CLQ in Guangzhou from 2010 to 2018; (3) identify the main obstacle factors affecting the improvement of the CLQ in Guangzhou. The potential scientific contributions of this study include (1) exploring the potential of using multi-source remote sensing data in the comprehensive evaluation of the CLQ; (2) providing scientific guidance for improving CLQ in Guangzhou, increasing food production, and ensuring regional food security. 


\section{Materials and Methods}

\subsection{Study Area}

Guangzhou $\left(112^{\circ} 57^{\prime}-114^{\circ} 03^{\prime} \mathrm{E}, 22^{\circ} 26^{\prime}-23^{\circ} 56^{\prime} \mathrm{N}\right)$ is the capital city of Guangdong Province and the largest city in southern China (Figure 1). Guangzhou contains 11 districts, including Yuexiu, Haizhu, Liwan, Tianhe, Baiyun, Huangpu, Nansha, Panyu, Huadu, Conghua, and Zengcheng. The minimum terrain altitude of Guangzhou is $0 \mathrm{~m}$, the maximum is $1181 \mathrm{~m}$, the mean is $107 \mathrm{~m}$, and the median is $34 \mathrm{~m}$. The terrain in Guangzhou is high in the northeast and low in the southwest, with mountains and hills in the north, hilly basins in the middle, and coastal alluvial plains in the south. The cultivated land is dominated by paddy fields, and rice is the main crop, with the rice planting area accounting for $88 \%$ of the total cultivated land area [41]. Other crops, such as vegetables, only account for approximately $10 \%$. The soil type of the cultivated land is lateritic red soil (Ferralsol, World Reference Base for Soil Resources 2015), which is characterized by strong acidity and low nutrient content. The mean annual temperature (MAT) in Guangzhou is $21.9{ }^{\circ} \mathrm{C}$, and MAT is higher in the south and lower in the north. The mean annual precipitation (MAP) in Guangzhou is about $1800 \mathrm{~mm}$, and MAP is lower in the south and higher in the north, and the precipitation is mainly concentrated from April to September. We chose Guangzhou as the study area because, in 2018, the Guangzhou municipal government proposed to build the "Vegetable Basket" production and circulation service system of the Guangdong-Hong Kong-Macao Greater Bay Area [42] with Guangzhou as the hub, aiming to provide more and better edible agricultural products. However, a large amount of cultivated land in Guangzhou has been converted into built-up land due to urbanization [43]. In this context, the CLQ in Guangzhou will be a key factor in achieving the goal of providing more and better edible agricultural products to a large extent. Therefore, it is urgent and important to carry out a spatiotemporal evaluation of the CLQ in Guangzhou to promote the efficient improvement of the CLQ.
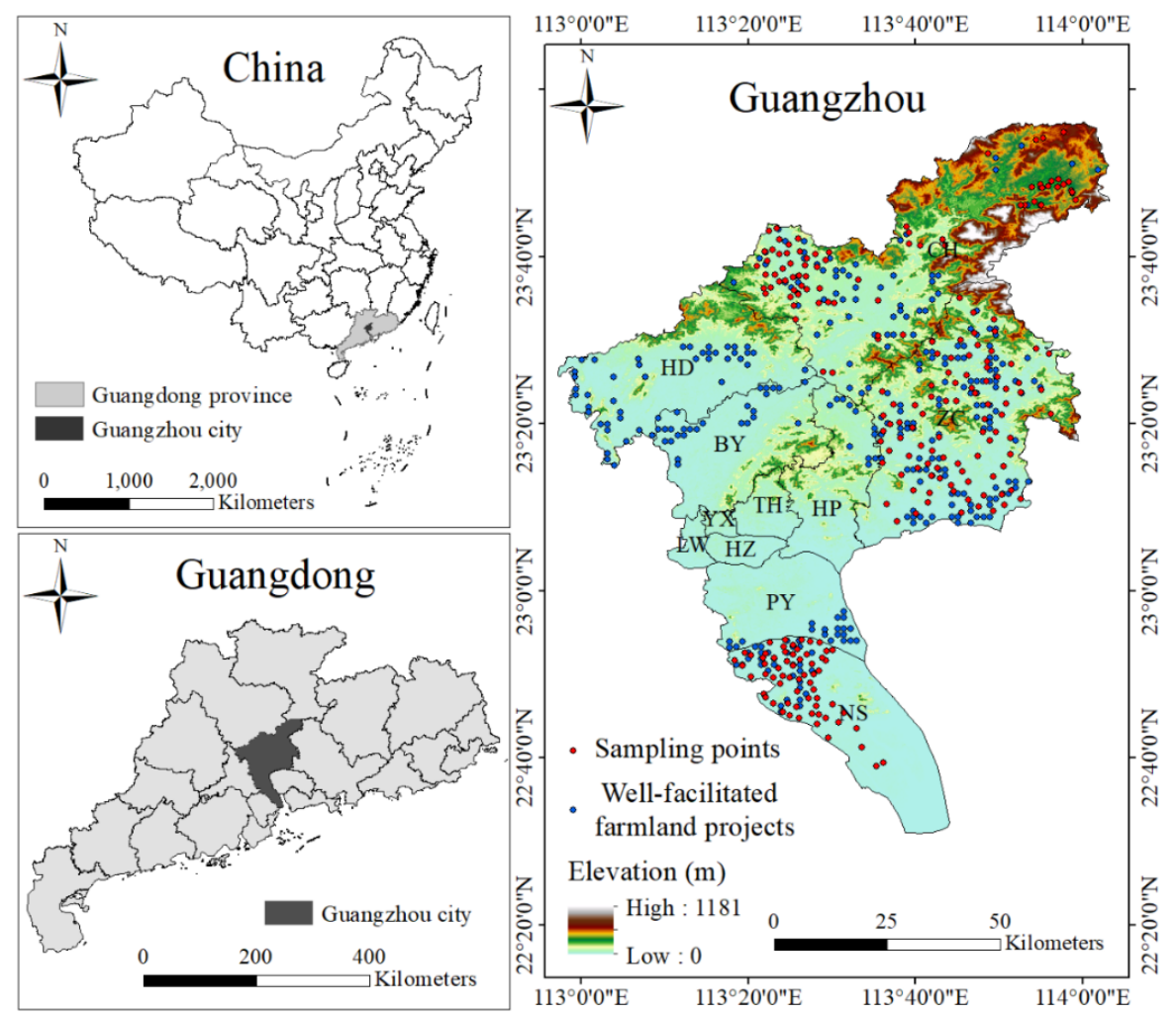

Figure 1. Overview map of the study area. $\mathrm{CH}$ : Conghua district; ZC: Zengcheng district; HP: Huangpu district; NS: Nansha district; HD: Huadu district; TH: Tianhe district; BY: Baiyun district; HZ: Haizhu district; PY: Panyu district; LW: Liwan district. 


\subsection{CLQ Evaluation Method}

\subsubsection{The Definition of CLQ}

This study defined the CLQ from four aspects, including soil fertility, natural conditions, construction level, and cultivated land productivity. Soil fertility is the foundation of crop growth and is the most critical indicator used to measure the CLQ [44,45]. The natural conditions of cultivated land can reflect some of the background properties that are closely related to the CLQ $[27,33]$. Cultivated land is a semi-artificial and semi-natural ecosystem; thus, the impact of construction level on the CLQ cannot be ignored [15,17]. The productivity capacity of cultivated land is the most direct manifestation of the CLQ [46] and should be taken into account.

\subsubsection{Indicator Selection}

Based on the proposed definition of CLQ, eight indicators were selected by integrating multi-source remote sensing data to construct a comprehensive CLQ indicator system (Table 1).

Table 1. The indicator system for evaluating cultivated land quality.

\begin{tabular}{|c|c|c|c|c|c|}
\hline Target & Definition & Indicator & $\begin{array}{l}\text { Calculation } \\
\text { Method }\end{array}$ & Grade & Weight \\
\hline \multirow{8}{*}{ Cultivated land quality } & \multirow{2}{*}{ Soil fertility } & Soil fertility size & $\begin{array}{l}\text { Mean of NDVI for } \\
\text { three consecutive } \\
\text { years }\end{array}$ & $\begin{array}{l}\text { High: }>0.7 \\
\text { Medium: } 0.5-0.7 \\
\text { Low: }<0.5\end{array}$ & 0.1403 \\
\hline & & Soil fertility stability & $\begin{array}{l}\text { CV of NDVI for } \\
\text { three consecutive } \\
\text { years }\end{array}$ & $\begin{array}{c}\text { High: }<5 \% \text {; } \\
\text { Medium: 5-10\%; } \\
\text { Low: }>10 \%\end{array}$ & 0.0954 \\
\hline & \multirow{2}{*}{ Natural conditions } & Slope & $\begin{array}{l}\text { Steepness of the } \\
\text { cultivated land }\end{array}$ & $\begin{array}{l}\text { High: }<2^{\circ} \\
\text { Medium: } 2-5^{\circ} \\
\text { Low: }>5^{\circ}\end{array}$ & 0.1094 \\
\hline & & Topsoil texture & $\begin{array}{l}\text { Ratio of sand, clay, } \\
\text { and loam }\end{array}$ & $\begin{array}{l}\text { High: Fine; } \\
\text { Medium: Medium; } \\
\text { Low: Coarse. }\end{array}$ & 0.0805 \\
\hline & \multirow{2}{*}{ Construction level } & Road accessibility & $\begin{array}{l}\text { The distance from } \\
\text { the cultivated land } \\
\text { to the nearest road }\end{array}$ & $\begin{array}{l}\text { High: }<0.5 \mathrm{~km} ; \\
\text { Medium: } 0.5-1.5 \mathrm{~km} \text {; } \\
\text { Low: }>1.5 \mathrm{~km} .\end{array}$ & 0.1234 \\
\hline & & Centralized contiguity & $\begin{array}{c}\text { Contig landscape } \\
\text { index }\end{array}$ & $\begin{array}{c}\text { High: }>0.85 \\
\text { Medium: } \\
\text { Low }:<5-0.75 \\
\text { L }\end{array}$ & 0.1008 \\
\hline & \multirow{2}{*}{$\begin{array}{l}\text { Cultivated land } \\
\text { productivity }\end{array}$} & $\begin{array}{l}\text { High productivity } \\
\text { capacity }\end{array}$ & $\begin{array}{l}\text { Mean of the NPP } \\
\text { for three } \\
\text { consecutive years }\end{array}$ & $\begin{array}{c}\text { High: }>600 \text {; } \\
\text { Medium: 450-600; } \\
\text { Low: }<450 \text {. }\end{array}$ & 0.1882 \\
\hline & & $\begin{array}{l}\text { Stable productivity } \\
\text { capacity }\end{array}$ & $\begin{array}{l}\text { CV of NPP for } \\
\text { three consecutive } \\
\text { years }\end{array}$ & $\begin{array}{c}\text { High: }<5 \% \text {; } \\
\text { Medium: 5-10\%; } \\
\text { Low: }>10 \%\end{array}$ & 0.1620 \\
\hline
\end{tabular}

The indicators used to evaluate soil fertility are soil fertility size and stability. Soil fertility size represents whether the current soil fertility is good, while soil fertility stability focuses on the state of soil fertility over a period of time. Soil fertility is affected by many factors, but the growth status of the vegetation can be used as a direct reflection of soil fertility [47]. Normalized Difference Vegetation Index (NDVI) is obtained from remote sensing images and can accurately reflect the growth of vegetation; thus, it is often referred to as the "soil fertility index" and has been used to fully characterize the soil fertility of cultivated land $[37,48]$. In this study, we used the mean of NDVI and coefficient of variation (CV) of NDVI of cultivated land for three consecutive years to characterize the size and stability 
of soil fertility, respectively. For soil fertility size, we first calculated the average NDVI within one year and then calculated the average NDVI for three consecutive years. Due to weather conditions, high-quality remote sensing images (cloud cover was less than 10\%) within one year were concentrated from September-November. September-November is a critical period for crop growth and harvesting in Guangzhou [49]. Therefore, the average NDVI during this period can effectively characterize the soil fertility of cultivated land. If the mean of NDVI is larger and the CV of NDVI is smaller for three consecutive years, then the soil fertility of cultivated land is better.

To evaluate the natural conditions of the cultivated land, we chose the slope and topsoil texture, which are the most frequently used and representative indicators due to their wide availability $[50,51]$. Previous studies have found that the slope is closely related to CLQ; that is, the greater the slope, the worse the CLQ [30]. Moreover, topsoil texture $(0-30 \mathrm{~cm})$ is most relevant to soil quality and crop growth, which is widely used in many previous CLQ evaluation studies [11,40]. If the slope is smaller and the topsoil texture is fine, then the natural conditions of the cultivated land are better.

To facilitate field production activities and meet the needs of agricultural mechanized production, farmers usually build a sound field road system and carry out land consolidation projects [19]. Therefore, in this study, road accessibility and centralized connectivity were used to represent the construction level of the cultivated land. Road accessibility refers to the distance from the cultivated land to the nearest road [52]. Centralized connectivity refers to whether the cultivated land is connected and to which degree of connectivity. In this study, the CONTIG landscape index was used to represent the centralized connectivity of cultivated land. The CONTIG index is a contiguity index, which can effectively assess the spatial connectedness of objects [53]. If road accessibility is smaller and centralized connectivity is larger, then the construction level of the cultivated land is better.

The productivity capacity of cultivated land was evaluated from the perspectives of the high productivity capacity and the stable productivity capacity. Previous studies have shown that net primary productivity (NPP) derived from MODIS 17 A3 (MOD17A3) can effectively characterize the productivity level of cultivated land [54,55]. The advantage of using NPP is that time-series data are readily available, and they can serve as a common comparable unit across different crop types [55]. In this study, we used the mean of NPP and the CV of NPP for three consecutive years to represent the high productivity capacity and stable productivity capacity of cultivated land, respectively. If the mean of NPP is large and the CV of the NPP is small for three consecutive years, then the cultivated land productivity is better.

\subsubsection{Calculation of the CLQ index}

The CLQ index was used to evaluate CLQ and mainly consists of three steps: (1) indicator selection and weight determination; (2) grading and scoring indicators; (3) calculation of the weighted sum of different indicators [10]. The impact of different evaluation indicators on the CLQ should be different; that is, their weight values are different [32]. Therefore, it is critical to set appropriate weight values for the evaluation indicators. In this study, we consulted ten experts from Guangdong Academy of Agricultural Sciences and South China Agricultural University in the form of questionnaires. They ranked the importance of the selected indicators. We combined the expert survey results with an analytic hierarchy process (AHP) to calculate the weight coefficients. In addition, the weight results passed the consistency test (consistency ratio value less than 0.1) [56]. We divided each evaluation indicator into three grades: high, medium, and low (Table 1). The grading of slope refers to China's national standard: the regulation for gradation of agricultural land quality [25]. The grading of the topsoil texture refers to the classification standard of the Harmonized World Soil Database (http:/ / www.fao.org/soils-portal/, accessed on 10 October 2020). The grading of road accessibility refers to a previous study on CLQ evaluation [57]. The grading of the remaining five indicators is based on Jenks classification, which can reduce the intra-class variance and maximize the inter-class variance [58]. We used the scoring 
method to score the high, medium, and low grades as 3, 2, and 1, respectively. Finally, we calculated the CLQ index as follows:

$$
C L Q I=\sum_{i=1}^{n} W_{i} \times Y_{i}
$$

where CLQI is the CLQ index; $W_{i}$ is the weight of the evaluation indicator; $Y_{i}$ is the score of the evaluation indicator; $n$ is the number of evaluation indicators ( $n=8$ in this study).

\subsubsection{Grading the CLQ index}

The $C L Q$ index ranges from 1.00 to 3.00. The larger the index is, the better the $C L Q$. In this study, the CLQ was divided into three grades, including high quality, medium quality, and low quality, according to the following criteria:

$$
C L Q \text { grade }= \begin{cases}\text { High }- \text { quality } & 2.40 \leq C L Q I \leq 3.00 \\ \text { Medium }- \text { quality } & 2.10 \leq C L Q I<2.40 \\ \text { Low }- \text { quality } & 1.00 \leq C L Q I<2.10\end{cases}
$$

\subsection{Data Sources and Preprocessing}

\subsubsection{Multi-Source Data}

Detailed information about the data used in this study is presented in Table 2. The cultivated land data for Guangzhou were obtained from China's National Land Use and Cover Change (CNLUCC) dataset. The dataset was generated using a uniform classification method with visual interpretation based on Landsat images, and it was provided by the Data Center for Resources and Environmental Sciences, Chinese Academy of Sciences. The overall accuracy of the dataset was $>90 \%$ [59].

\begin{tabular}{|c|c|c|c|c|c|}
\hline Data & Indicator & Source & Year & Attribute & Resolution \\
\hline $\begin{array}{l}\text { Landsat/ } \\
\text { Sentinel-2 images }\end{array}$ & Soil fertility & $\begin{array}{l}\text { USGS Earth Resources Observation and Science Center } \\
\text { (http:/ / earthexplorer.usgs.gov/, } \\
\text { accessed on } 11 \text { August 2020) }\end{array}$ & $\begin{array}{l}\text { 2009-2011; } \\
\text { 2014-2019. }\end{array}$ & $\begin{array}{l}\text { Raster } \\
\text { Raster }\end{array}$ & $\begin{array}{l}30 \times 30 \mathrm{~m} \\
10 \times 10 \mathrm{~m}\end{array}$ \\
\hline DEM & Slope & $\begin{array}{c}\text { Geospatial Data Cloud } \\
\text { (http://www.gscloud.cn/, } \\
\text { accessed on } 12 \text { October 2020) }\end{array}$ & 2011 & Raster & $30 \times 30 \mathrm{~m}$ \\
\hline $\begin{array}{l}\text { Harmonized } \\
\text { World Soil } \\
\text { Database }\end{array}$ & Topsoil texture & $\begin{array}{l}\text { FAO Soils portal (http:/ / www.fao.org/soils-portal, } \\
\text { accessed on } 10 \text { October 2020) }\end{array}$ & 2009 & Raster & $1 \times 1 \mathrm{~km}$ \\
\hline Road vector data & Road accessibility & $\begin{array}{c}\text { OpenStreetMap } \\
\text { (https:/ / www.openstreetmap.org, } \\
\text { accessed on } 18 \text { October 2020) }\end{array}$ & $2010 / 2015 / 2018$ & Vector & - \\
\hline $\begin{array}{l}\text { China's National } \\
\text { Land Use and } \\
\text { Cover Change }\end{array}$ & $\begin{array}{l}\text { Centralized } \\
\text { contiguity }\end{array}$ & $\begin{array}{l}\text { Resource and Environment Data Cloud Platform } \\
\text { (http:/ / www.resdc.cn, accessed on } 27 \text { June 2020) }\end{array}$ & $2010 / 2015 / 2018$ & Raster & $30 \times 30 \mathrm{~m}$ \\
\hline $\begin{array}{l}\text { MODIS 17A3 } \\
\text { NPP }\end{array}$ & $\begin{array}{l}\text { Cultivated land } \\
\text { productivity }\end{array}$ & $\begin{array}{c}\text { NASA LAADS DAAC } \\
\text { (http:/ / e4ft101.cr.usgs.gov/MOLT, } \\
\text { accessed on } 25 \text { May 2021) }\end{array}$ & $\begin{array}{l}\text { 2009-2011; } \\
\text { 2014-2019. }\end{array}$ & Raster & $500 \times 500 \mathrm{~m}$ \\
\hline
\end{tabular}

Table 2. Data information.

The NDVI was calculated to evaluate the soil fertility of the cultivated land based on the Landsat Thematic Mapper/Operational Land Imager (TM/OLI) data in ENVI 5.3. However, due to the quality of Landsat remote sensing image being not good (cloud cover was greater than $10 \%$ ) in 2018, we chose a high-quality Sentinel-2 image with higher spatial resolution $(10 \times 10 \mathrm{~m})$ as a substitute. To maintain the same resolution as the Landsat images, the Sentinel-2 image was resampled to $30 \mathrm{~m}$.

Using ArcGIS (version 10.6; Software for Spatial Analysis; Environmental Systems Research Institute, Redlands, CA, USA, 2019), the slope of the cultivated land was extracted based on the Digital Elevation Model (DEM) data, and the distance from each cultivated land pixel to the nearest road was calculated. In this study, the Fragstats (version 4.2; Software for Categoracal Map Patterns; Oregon State University, Corvallis, OR, USA, 2017) 
was used to calculate the Contig landscape index. The calculation of the mean and CV of the NPP was conducted in ENVI 5.3. To unify the evaluation unit, all data were resampled to $30 \mathrm{~m}$.

\subsubsection{Validation Dataset}

In this study, the validation data consisted of the comprehensive evaluation results of field-measured indicators, including soil organic matter, total nitrogen, available phosphorus, available potassium, $\mathrm{pH}$, slope, topsoil texture, soil thickness, soil bulk density, soil parent material, irrigation guaranteed rate, drainage conditions, yield. Due to the limitations of the acquisition of the validation data, we took the Conghua, Zengcheng, and Nansha districts as examples to verify the results. There were 75 ground monitoring points in Conghua district, 89 ground monitoring points in Zengcheng district, and 65 ground monitoring points in Nansha district. The number and spatial location of the ground sampling points in the three districts were the same for all study years (Figure 1).

To further verify the evaluation results of the CLQ in the entire study area, we chose the spatiotemporal distribution data for well-facilitated farmland (i.e., high-quality cultivated land formed through land consolidation and construction within a certain period) in Guangzhou as an additional validation dataset. Well-facilitated farmland construction is considered to be a strategic measure to ensure China's national food security $[57,60]$. The purpose of well-facilitated farmland construction is to improve the comprehensive quality of the cultivated land; thus, its spatial distribution data consisted of a validation dataset suitable for the needs of this study. According to China's National Overall Plan for Well-Facilitated Farmland Construction, when the construction of well-facilitated farmland is completed, the CLQ grade will be significantly improved. Therefore, we reasonably believe that the CLQ in a well-facilitated farmland construction area is significantly better than that in a non-well-facilitated farmland construction area. We further verified the accuracy of the evaluation results for the study area by comparing the CLQ index values (obtained in this study) of a well-facilitated farmland and non-well-facilitated farmland.

Guangzhou started implementing the well-facilitated farmland construction project in 2012, and by the end of 2018, 309 well-facilitated farmland construction projects had been completed (Figure 1). Therefore, we used the spatial distribution data for the wellfacilitated farmland constructed in 2015 and 2018 to verify the evaluation results of the CLQ for 2015 and 2018, respectively.

\subsection{Obstacle Factor Diagnosis Model}

In this study, the obstacle factor diagnosis model was used to identify the main factors affecting the improvement of the CLQ. The obstacle factor diagnosis model identifies the obstacle factors based on three basic variables: the factor contribution degree, indicator deviation degree, and obstacle degree [28]. The greater the obstacle degree of the evaluation indicator is, the stronger its negative effect on the improvement of the CLQ. The equation for calculating the obstacle degree is as follows:

$$
O_{i}=\frac{I_{i} \times W_{i}}{\sum_{i=1}^{n}\left(I_{i} \times W_{i}\right)} \times 100 \%
$$

where $O_{i}$ is the obstacle degree of the $i$ th indicator; $W_{i}$ is the factor contribution degree of the $i$ th indicator, which is equal to the weight of the indicator; $I_{i}$ is the deviation degree of the $i$ th indicator, which is equal to the difference between the highest value and the actual value of the indicator. Here, $I_{i}=3.00-Y_{i}$. 


\section{Results}

\subsection{Accuracy Verification of the CLQ}

The results of CLQ based on field measurements (measured) and the remote sensing evaluation (evaluated) are shown in Figure 2. In the Conghua district, there was a good spatial consistency between the measured results and the evaluation results. High-quality cultivated land was mainly concentrated in the central and western regions, and mediumand low-quality cultivated land was widely distributed throughout the entire region. In the Zengcheng district, there is a relatively good spatial consistency between the measured results and the evaluation results. High-quality cultivated land was concentrated in the southeastern and northern regions, medium-quality cultivated land was widely distributed, and low-quality cultivated land occupied a relatively small proportion. In the Nansha district, there is a slightly larger spatial difference between the measured results and the evaluation results in 2010. However, in 2015 and 2018, the evaluation results were in good agreement with the measured results. Overall, the verification results can largely indicate that the resultant CLQ based on remote sensing evaluation was reliable.
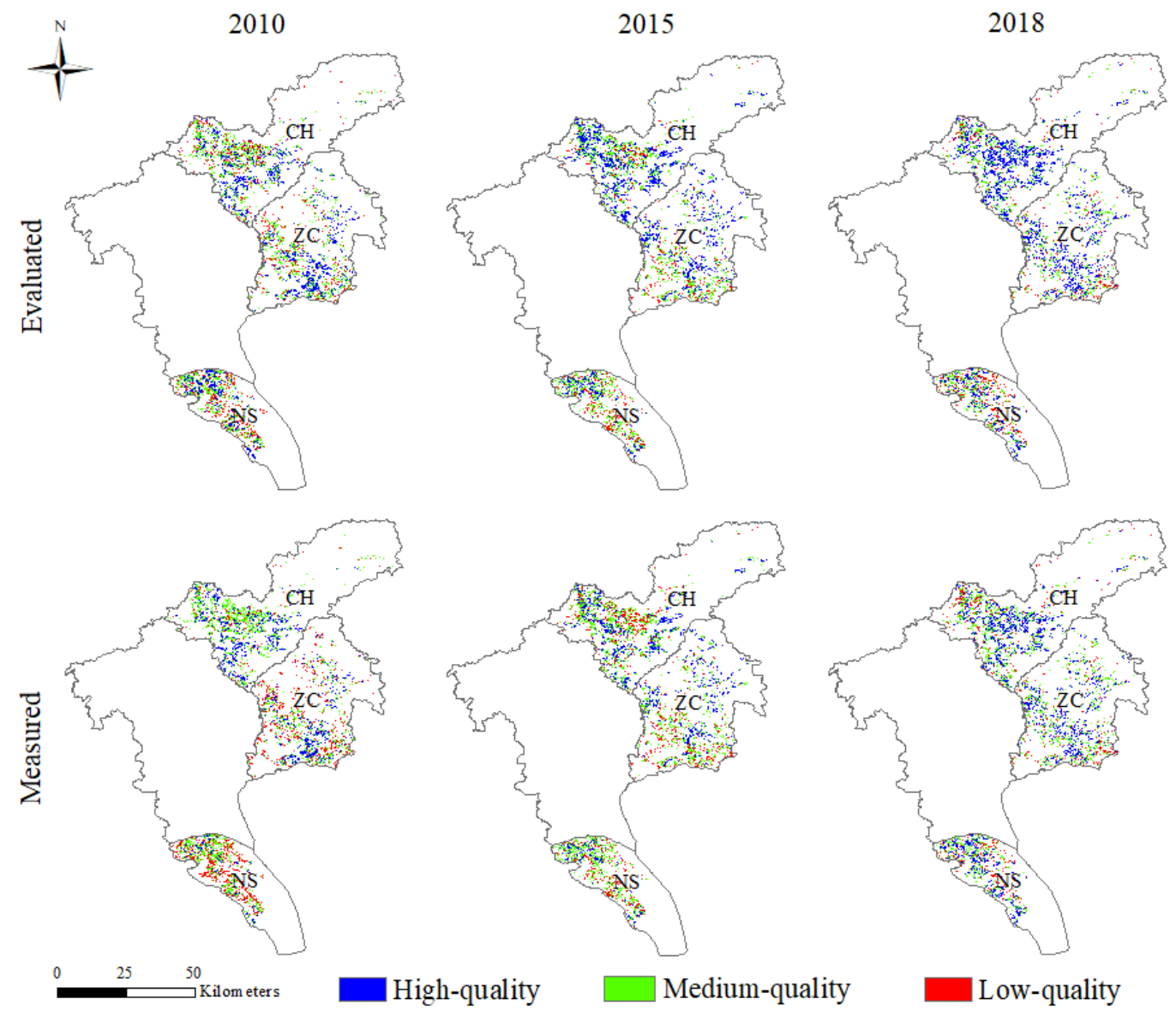

Figure 2. Spatial distribution of the cultivated land quality from 2010 to 2018 based on field measurements (measured) and the remote sensing evaluation (evaluated). CH: Conghua district; ZC: Zengcheng district; NS: Nansha district.

The grade difference between the remote sensing evaluation results and the measured results of CLQ is shown in Figure 3. From 2010 to 2018, in the Conghua district, the average $49 \%$ of CLQ had a grade difference of 0 , the average $40 \%$ of CLQ had a grade difference of 1 (including 1 and -1 ), and the average 11\% of CLQ had a grade difference of 1 (including 2 and -2). In the Zengcheng district, the average $48 \%$ of CLQ had a grade difference of 0 , the average $40 \%$ of CLQ had a grade difference of 1 (including 1 and -1 ), and the average $12 \%$ of CLQ had a grade difference of 1 (including 2 and -2). In the Nansha district, about 
40\% of CLQ had a grade difference of 0 in 2010, which was relatively low. In 2015 and 2018, the average $47 \%$ of CLQ had a grade difference of 0 , the average $39 \%$ of CLQ had a grade difference of 1 (including 1 and -1 ), and the average 14\% of CLQ had a grade difference of 2 (including 2 and -2 ). This indicated that the remote sensing evaluation results of CLQ were in good agreement with the measured results.

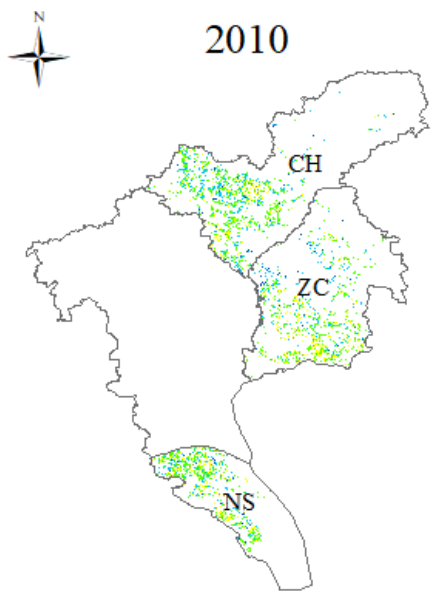

CLQ grade difference

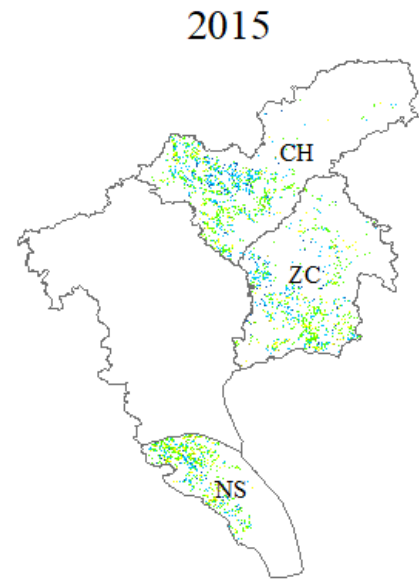

$\square-2 \square-1 \quad \square 0 \quad \square 1$

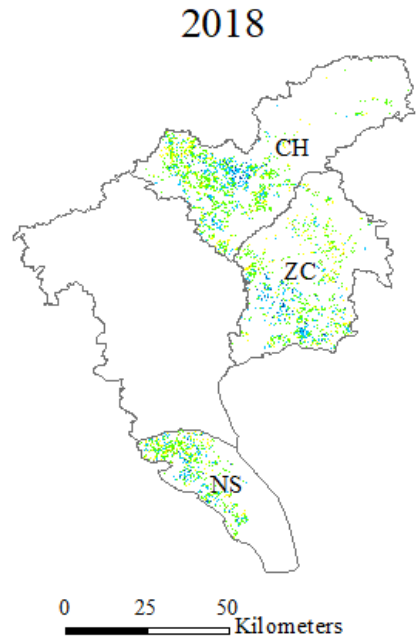

Figure 3. Grade difference (Evaluated grade minus Measured grade) between the remote sensing evaluation results and the measured results of cultivated land quality (CLQ) from 2010 to 2018. CH: Conghua district; ZC: Zengcheng district; NS: Nansha district.

The comparison of the CLQ results for the well-facilitated farmland and the nonwell-facilitated farmland is shown in Table 3. In 2015 and 2018, the CLQ index of the well-facilitated farmland construction area was significantly greater than that of the nonwell-facilitated farmland construction area. Moreover, the CLQ of the well-facilitated farmland construction areas was mainly high quality (about 50\%), while the CLQ in the non-well-facilitated farmland construction area was mainly medium quality (about 40\%) in these two years. These results are consistent with the reasonable hypothesis made in this study, indicating that the resultant CLQ evaluation using integrated remote sensing data is reliable.

Table 3. Comparison of the cultivated land quality (CLQ) of the well-facilitated farmland and non-well-facilitated farmland.

\begin{tabular}{cccc}
\hline Year & Results & Well-Facilitated Farmland & Non-Well-Facilitated Farmland \\
\hline \multirow{3}{*}{2015} & CLQ index & 2.30 & 1.90 \\
& High quality & $45.77 \%$ & $25.69 \%$ \\
& Medium quality & $40.18 \%$ & $41.73 \%$ \\
& Low quality & $14.05 \%$ & $32.58 \%$ \\
\multirow{2}{*}{2018} & CLQ index & 2.33 & 2.01 \\
& High quality & $52.09 \%$ & $28.38 \%$ \\
& Medium quality & $28.51 \%$ & $44.09 \%$ \\
& Low quality & $19.40 \%$ & $27.53 \%$ \\
\hline
\end{tabular}




\subsection{Spatiotemporal Changes of the $C L Q$}

\subsubsection{Spatiotemporal Changes of CLQ in Guangzhou}

The CLQ index in Guangzhou increased steadily from 2010 to 2018 (Figure 4), indicating that the CLQ in Guangzhou continuously improved. From 2010 to 2018, the high-quality cultivated land increased by about 10,000 ha, and the proportion increased by $13.65 \%$. The medium-quality and low-quality cultivated land decreased by 12,000 and $8000 \mathrm{ha}$, respectively, and their proportions decreased by $8.10 \%$ and $5.55 \%$, respectively (Table 4 ).

Spatially, from 2010 to 2018, the high-quality cultivated land in the eastern and northern parts of Guangzhou expanded continuously, and the medium- and low-quality cultivated lands decreased significantly, which indicated that the CLQ in these two regions continuously improved. In the western and southern parts of Guangzhou, the high-quality cultivated land initially decreased and then increased. Correspondingly, the mediumand low-quality cultivated land initially increased and then decreased. The CLQ in these two regions improved slightly overall. The CLQ in the central region was low, and there was no significant change during the study period (Figure 5).

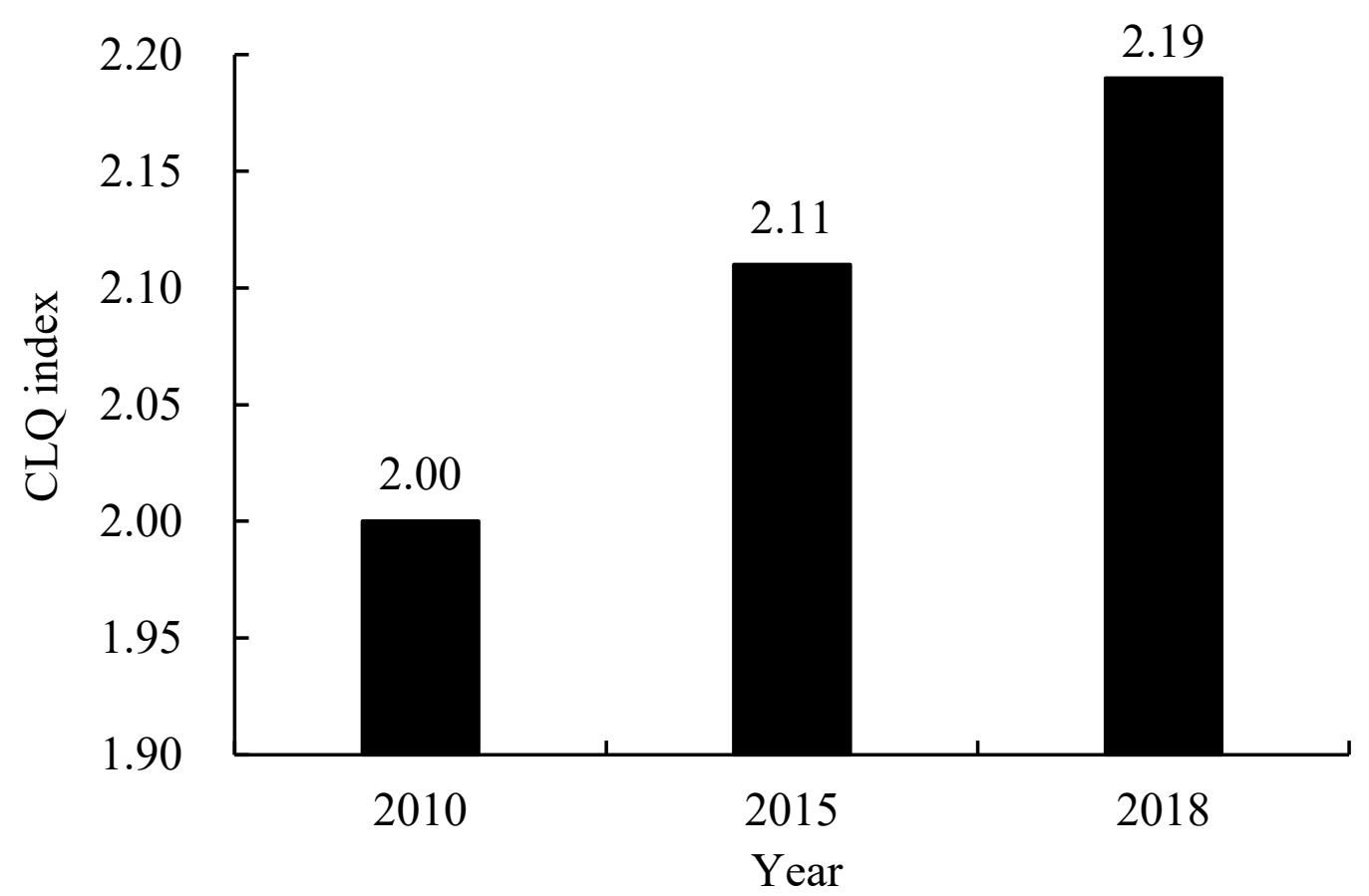

Figure 4. The changing trend of cultivated land quality (CLQ) index in Guangzhou from 2010 to 2018.

Table 4. Cultivated land quality evaluation results of Guangzhou from 2010 to 2018.

\begin{tabular}{ccccccc}
\hline \multirow{2}{*}{ Year } & \multicolumn{2}{c}{$\begin{array}{c}\text { High Quality } \\
\text { Area (ha) }\end{array}$} & Percent & Medium Quality & \multicolumn{2}{c}{ Low Quality } \\
& 29,796 & $28.26 \%$ & 45,662 & $43.30 \%$ & 29,996 & $28.44 \%$ \\
\hline 2010 & 34,782 & $35.14 \%$ & 39,786 & $40.20 \%$ & 24,408 & $24.66 \%$ \\
2015 & 40,045 & $41.91 \%$ & 33,642 & $35.20 \%$ & 21,871 & $22.89 \%$ \\
\hline
\end{tabular}



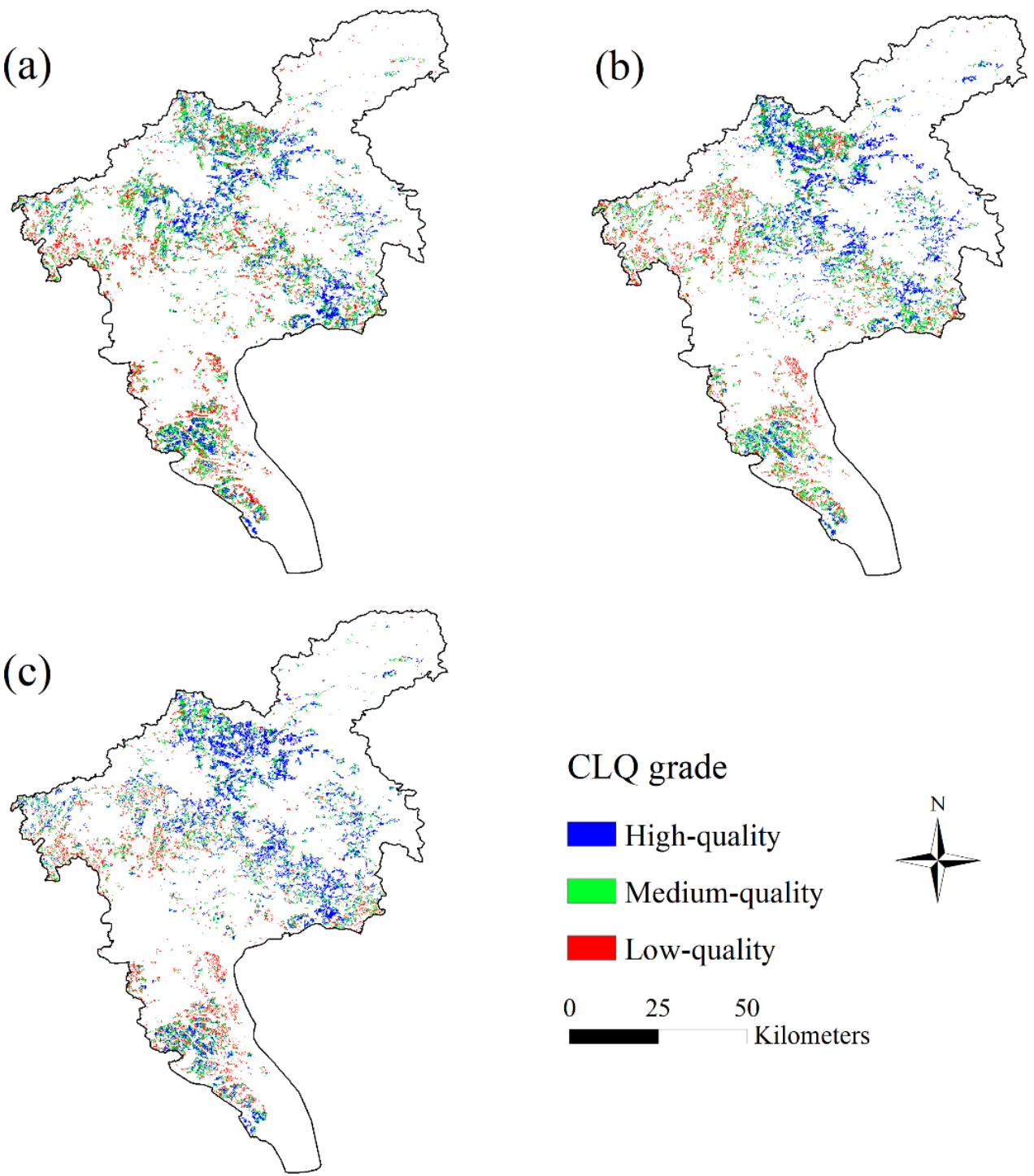

CLQ grade

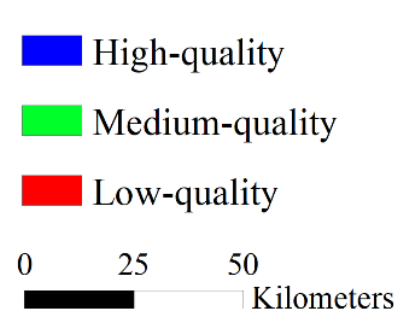

Figure 5. Spatial distribution of the cultivated land quality (CLQ) grade in Guangzhou: (a) 2010; (b) 2015; (c) 2018 .

\subsubsection{Spatiotemporal Changes of CLQ in Unchanged/Lost/Gained Area}

Spatiotemporal changes of CLQ in the unchanged area (cultivated land that had not been converted to other land use types during the study period) are presented in Table 5 . In these three different periods, the quality grade of about $50 \%$ of the cultivated land did not change. The proportion of cultivated land with an improved quality grade (including improvement by 2 grades and 1 grade) was greater than that of the cultivated land with a decreased quality grade (including a decrease by 2 grades and 1 grade). This indicated that the quality of the unchanged cultivated land improved from 2010 to 2018.

Spatially, the unchanged cultivated land with no change in quality grade was widely distributed throughout the entire study area. The unchanged cultivated land with improved quality (including improvement by 2 grades and 1 grade) was mainly concentrated in the eastern, northern, and southern parts of Guangzhou. The unchanged cultivated land with decreased quality (including a decrease by 2 grades and 1 grade) was mainly concentrated in the western part of Guangzhou (Figure 6). 
Table 5. Change characteristics of CLQ in unchanged area.

\begin{tabular}{|c|c|c|c|c|c|c|}
\hline Year & $\begin{array}{l}\text { Statistical } \\
\text { Measure }\end{array}$ & $\begin{array}{c}\text { Improved } \\
\text { by } 2 \text { Grades }\end{array}$ & $\begin{array}{l}\text { Improved } \\
\text { by } 1 \text { Grade }\end{array}$ & $\begin{array}{c}\text { Grade } \\
\text { Unchanged }\end{array}$ & $\begin{array}{l}\text { Decreased } \\
\text { by } 1 \text { Grade }\end{array}$ & $\begin{array}{c}\text { Decreased } \\
\text { by } 2 \text { Grades }\end{array}$ \\
\hline \multirow{2}{*}{ 2010-2015 } & Area (ha) & 2438 & 15,772 & 35,051 & 15,683 & 1873 \\
\hline & Percent (\%) & 3.44 & 22.27 & 49.49 & 22.15 & 2.65 \\
\hline \multirow{2}{*}{ 2015-2018 } & Area (ha) & 3265 & 19,131 & 37,156 & 13,069 & 1143 \\
\hline & Percent $(\%)$ & 4.43 & 25.93 & 50.37 & 17.72 & 1.55 \\
\hline \multirow{2}{*}{ 2010-2018 } & Area (ha) & 3949 & 17,685 & 29,998 & 11,192 & 1531 \\
\hline & Percent (\%) & 6.14 & 27.48 & 46.61 & 17.39 & 2.38 \\
\hline
\end{tabular}
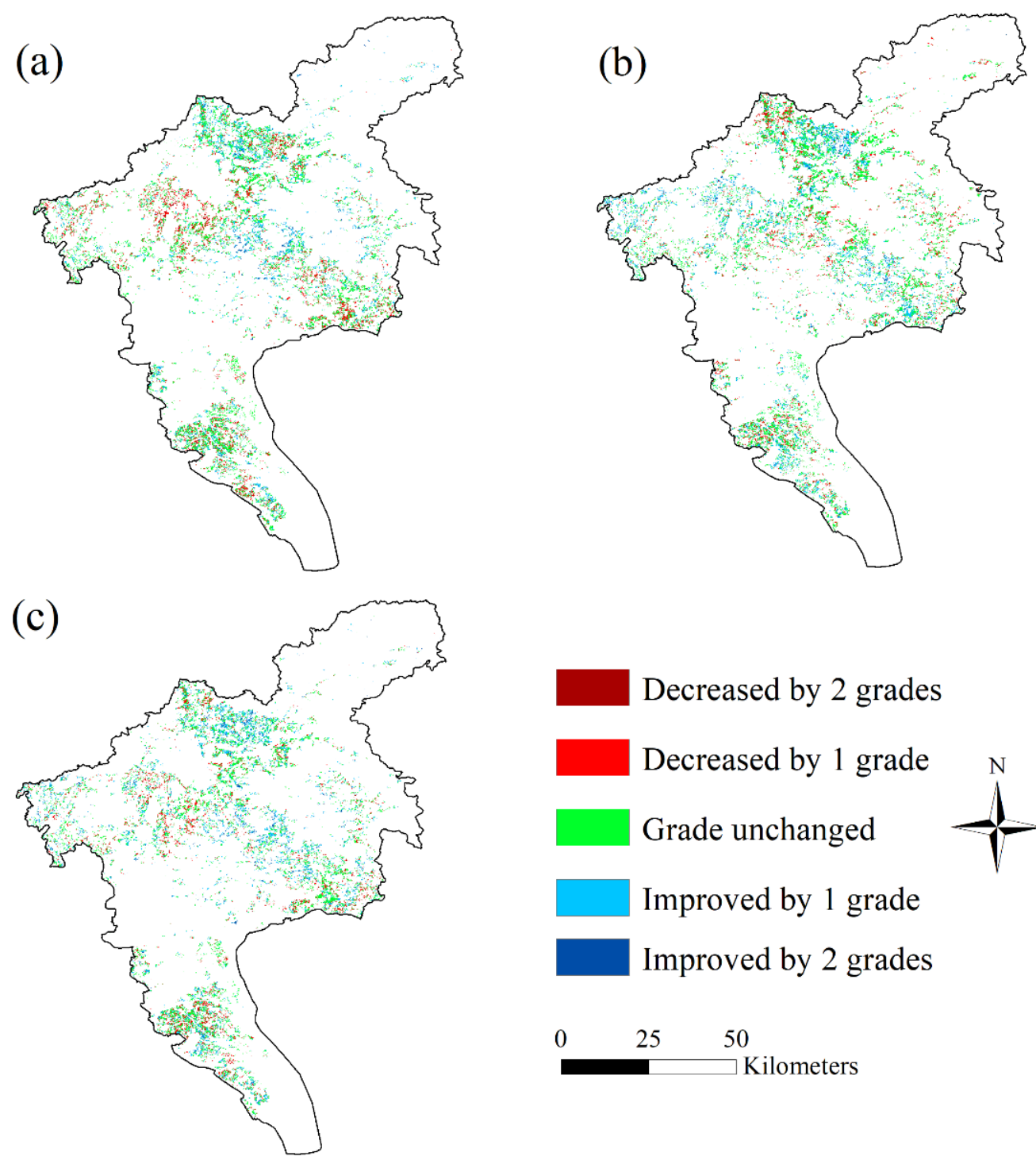

Decreased by 2 grades

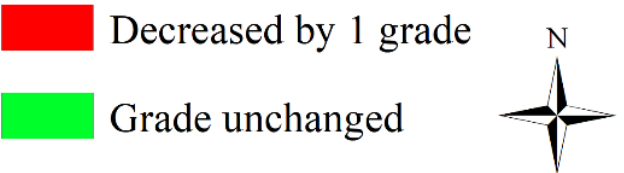

Improved by 1 grade

Improved by 2 grades

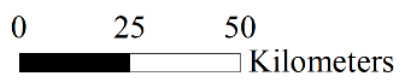

Figure 6. Spatial characteristics of the quality change of the unchanged cultivated land in the different study periods: (a) 2010-2015; (b) 2015-2018; (c) 2010-2018.

Spatiotemporal changes of CLQ in lost/gained area (including the lost cultivated land in the previous year and the gained cultivated land in the following year during the study periods) are presented in Table 6 . In these three different periods, the lost cultivated land (cultivated land converted to non-cultivated land) was mainly medium quality and low quality, accounting for about $77 \%$, while the gained cultivated land (non-cultivated land converted to cultivated land) was mainly high quality and medium quality, accounting for about $72 \%$. 
Table 6. Change characteristics of CLQ in changed area.

\begin{tabular}{|c|c|c|c|c|}
\hline Year & Lost/Gained area & High Quality & Medium Quality & Low Quality \\
\hline \multirow{4}{*}{ 2010-2015 } & Lost cultivated land (ha) & 7836 & 14,835 & 11,965 \\
\hline & Percent $(\%)$ & 22.63 & 42.83 & 34.54 \\
\hline & Gained cultivated land (ha) & 9160 & 11,067 & 7883 \\
\hline & Percent $(\%)$ & 32.59 & 39.37 & 28.04 \\
\hline \multirow{4}{*}{ 2015-2018 } & Lost cultivated land (ha) & 5691 & 10,570 & 8932 \\
\hline & Percent $(\%)$ & 22.59 & 41.96 & 35.45 \\
\hline & Gained cultivated land (ha) & 7845 & 7882 & 6068 \\
\hline & Percent $(\%)$ & 35.99 & 36.16 & 27.85 \\
\hline \multirow{4}{*}{ 2010-2018 } & Lost cultivated land (ha) & 9508 & 17,747 & 13,822 \\
\hline & Percent $(\%)$ & 23.15 & 43.20 & 33.65 \\
\hline & Gained cultivated land (ha) & 11,450 & 10,990 & 8706 \\
\hline & Percent $(\%)$ & 36.76 & 35.29 & 27.95 \\
\hline
\end{tabular}

There was large spatial heterogeneity in the quality changes of the lost/gained cultivated land. From 2010 to 2015 and from 2010 to 2018, the lost medium-quality and low-quality cultivated lands were mainly located in the southern and western parts of Guangzhou. The gained medium- and high-quality cultivated lands were mainly concentrated in the eastern and central-northern areas (Figure 7a,c). From 2015 to 2018, the lost medium- and low-quality cultivated lands were mainly located in the western and northern parts of Guangzhou. The gained medium- and high-quality cultivated lands were mainly concentrated in the eastern and southern areas (Figure $7 \mathrm{~b}$ ).
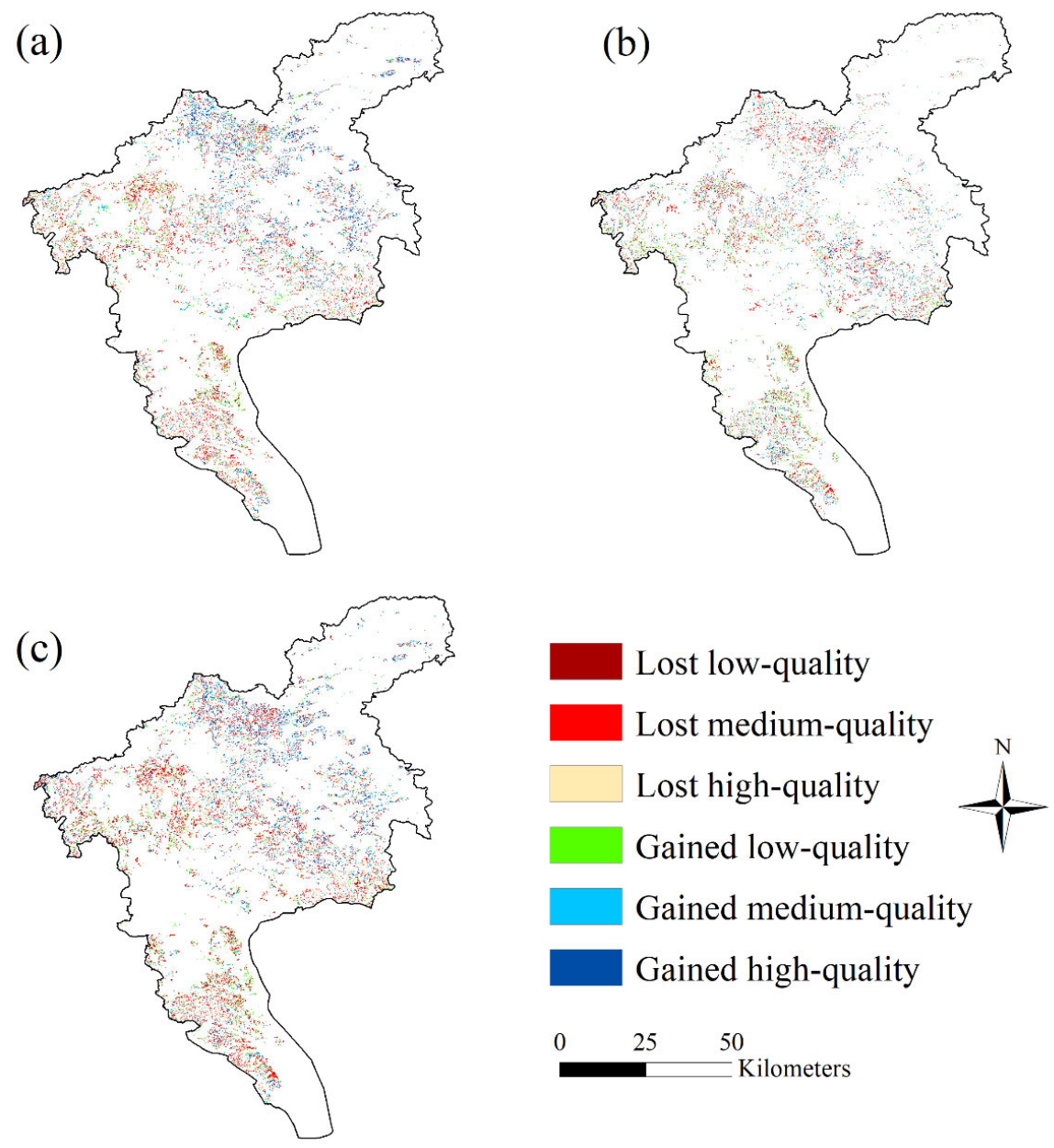

Figure 7. Spatial characteristics of the quality change of the lost/gained cultivated land in the different study periods: (a) 2010-2015; (b) 2015-2018; (c) 2010-2018. 


\subsection{Obstacle Factors Affecting the Improvement of $C L Q$}

Based on the obstacle factor diagnosis model, the obstacle degree of each evaluation indicator was calculated (Figure 8 ). The soil fertility size, high productivity capacity, and slope were the main obstacle factors to the CLQ in Guangzhou from 2010 to 2018. The sum of the obstacle degrees of the three indicators was about $50.0 \%$. In addition, the obstacle degree of the stable productivity capacity gradually increased from $12.1 \%$ in 2010 to $17.5 \%$ in 2018. The obstacle degree of the road accessibility gradually decreased from $15.1 \%$ in 2010 to $5.4 \%$ in 2018.

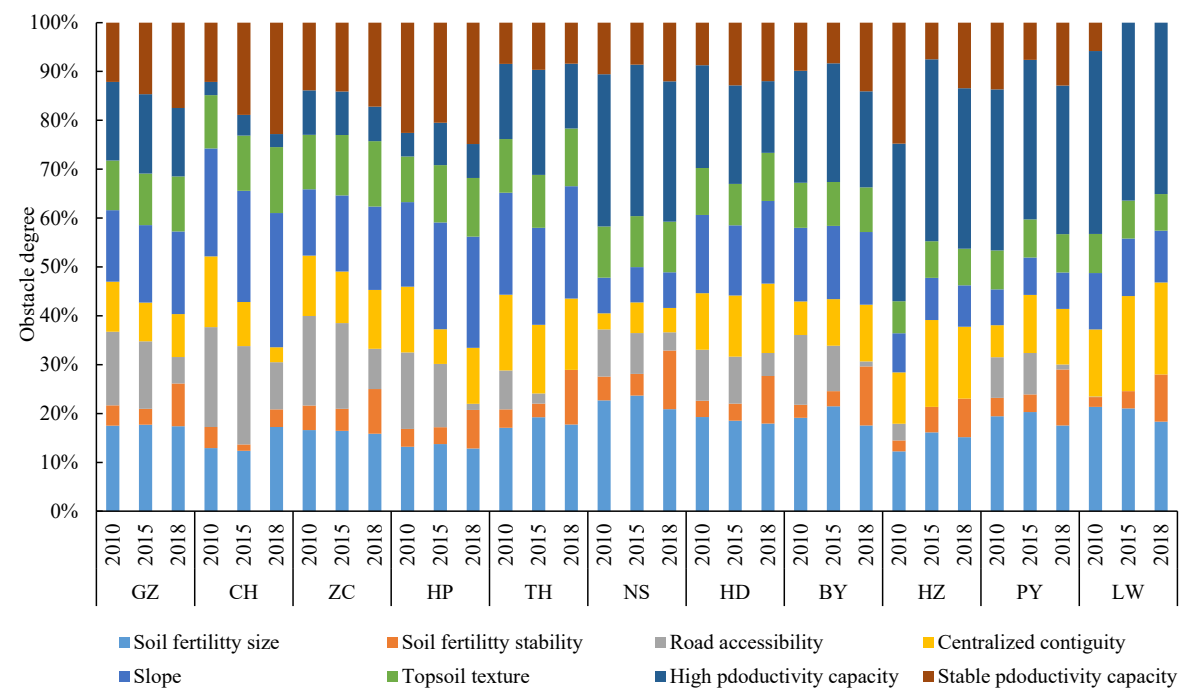

Figure 8. The obstacle degrees of the evaluation indicators in Guangzhou (GZ) and its 10 districts from 2010 to 2018. CH: Conghua district; ZC: Zengcheng district; HP: Huangpu district; TH: Tianhe district; NS: Nansha district; HD: Huadu district; BY: Baiyun district; HZ: Haizhu district; PY: Panyu district; LW: Liwan district.

The obstacle degrees of the evaluation indicators differed among the 10 districts in Guangzhou. From 2010 to 2018, slope was the largest obstacle factor of CLQ in Conghua, Huangpu and Tianhe districts, with an average obstacle degree of $24.1 \%, 20.6 \%$ and $21.2 \%$, respectively. High productivity capacity was the largest obstacle factor of CLQ in Nansha, Haizhu, Panyu and Liwan districts, with an average obstacle degree of $30.3 \%, 34.1 \%, 33.5 \%$ and $36.3 \%$, respectively. Soil fertility size, slope and stable productivity capacity were the main obstacles to the CLQ in Zengcheng district, and their obstacle degrees were $16.3 \%$, $15.4 \%$ and $15.1 \%$, respectively. High productivity capacity and soil fertility size were the main obstacles to the CLQ in Huadu and Baiyun districts, and their obstacle degrees were $18.7 \%, 18.6 \%, 22.3 \%$ and $19.4 \%$, respectively.

\section{Discussion}

\subsection{CLQ Evaluation Method Integrating Multi-Source Remote Sensing}

An efficient evaluation method is the basis for revealing the spatiotemporal patterns of CLQ. However, traditional evaluation methods need to acquire a large number of groundmeasured soil data, which is time-consuming and laborious, and the evaluation results depend on a spatial interpolation method. Different spatial interpolation methods will affect the evaluation results of CLQ [10], and thus, the spatial information of the CLQ cannot be reflected objectively. Satellite remote sensing data have the advantages of wide coverage, abundant historical data, and objective spatial information, which are suitable for the spatiotemporal evaluation of the CLQ.

The existing abundant remote sensing data can effectively support the comprehensive evaluation of the CLQ. However, previous studies have only focused on a single attribute of the CLQ, such as soil fertility or soil moisture $[35,37]$. Few studies have integrated 
multi-source remote sensing data to comprehensively evaluate the CLQ. In this study, a comprehensive indicator system for evaluating the CLQ was developed by integrating Landsat, Sentinel-2, and MODIS NPP data products. These remote sensing data and related products satisfy the spatial scale and temporal continuity requirements to reveal the spatiotemporal changes in the CLQ.

The verification for the accuracy of the results obtained in this study showed that the results of CLQ evaluation calculated by integrating multi-source remote sensing data were reliable. Our results on the spatial distribution of CLQ were also consistent with previous studies [49]. This indicated that the CLQ evaluation method integrating remote sensing data is reasonable and feasible.

\subsection{The Mechanism behind the Spatiotemporal Changes of CLQ in Guangzhou}

Previous studies have emphasized that formulating a specific policy and plan is an important measure for improving the CLQ [61,62]. Guangzhou has paid considerable attention to the protection and improvement of the CLQ and has formulated and implemented a series of strict cultivated land protection policies in recent years. For example, Guangzhou city started to construct well-facilitated farmland in 2012 and released the Action Plan for Cultivated Land Protection in 2014 to effectively improve the CLQ (http:/ / ghzyj.gz.gov.cn/, accessed on 1 February 2021). By the end of 2018, the construction area of the well-facilitated farmland in Guangzhou accounted for $63.58 \%$ of the total cultivated land area, which was helpful in the overall improvement of the CLQ.

At the same time, socio-economic development also promotes the improvement of the CLQ [63]. Economic growth enables governments to invest more funds in agricultural production activities [64]. Moreover, increasing subsidies to farmers can motivate them to actively protect and improve the CLQ [65]. After 2015, Guangzhou's municipal government issued a series of agricultural machinery purchases and subsidy implementation plans, which greatly improved the level of agricultural mechanization and strengthened farmer awareness of protecting and improving the CLQ.

In addition, rational planning of land use and crop planting structure is also a potential driving mechanism for improving the CLQ in Guangzhou (http://g.mnr.gov.cn/, accessed on 11 January 2021). Agronomic measures are also crucial to the improvement of CLQ. For example, increasing the application of organic fertilizer and planting green manure can improve the soil structure and enhance the ability of soil to retain fertilizer and water [66,67]. The development of agrotechnology has provided a lasting impetus for the improvement of the CLQ. High-quality seeds and cultivated land management technology adapted to local conditions can promote the continuous improvement of CLQ $[17,68]$.

\subsection{Corresponding Measures to Improve the CLQ in Guangzhou}

How to improve CLQ in a targeted manner is one of the purposes of carrying out the evaluation of CLQ [10]. The obstacle factor diagnosis model can identify the main factors that affect the improvement of CLQ. In this study, the diagnosis results showed that the soil fertility size, high productivity capacity, and slope were the main obstacle factors affecting the improvement of the CLQ in Guangzhou, while the obstacle degree of the stable productivity capacity gradually increased during the study period.

Lateritic red soil is the main soil type in the cultivated land in Guangzhou. Its typical characteristics are low nutrient contents and poor ability to retain fertilizer [69], which lead to soil fertility being one of the main obstacle factors affecting the improvement of the CLQ in Guangzhou. Relevant studies have shown that stakeholders can improve soil fertility through reasonable crop rotation, application of biofertilizers, and biochar amendment $[20,67,70]$.

The high productivity capacity had a great obstacle effect on the improvement of the CLQ, which may be the main reason that the yield per unit area of the grain crops in Guangzhou was significantly lower than that in Guangdong Province and China's national average level (Figure 9). This indicates that the production capacity of cultivated land in 
Guangzhou needs to be further improved. A large number of previous studies have shown that improving the utilization rates of water and fertilizer, rationally optimizing the spatial distribution of the crop production, and improving the agricultural production conditions can help increase the productivity of cultivated land [71-73].

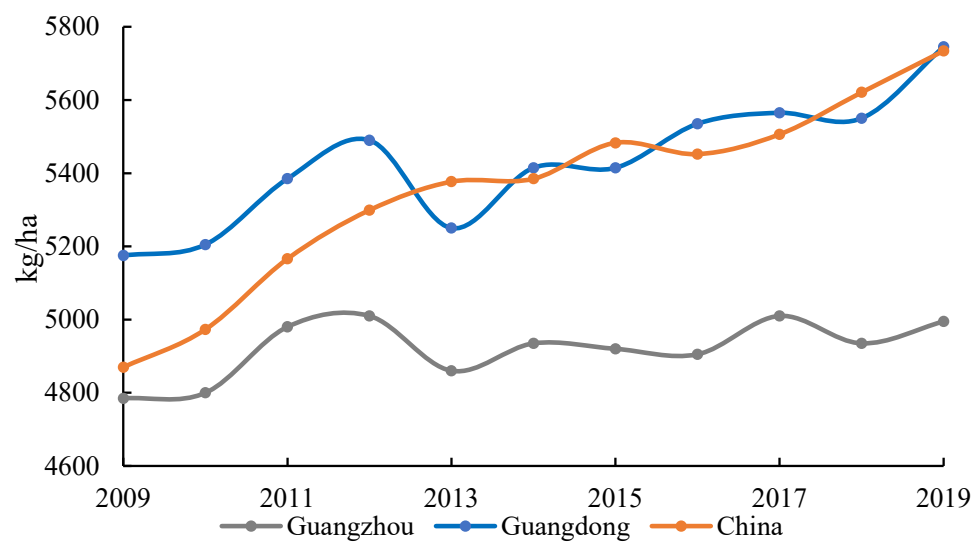

Figure 9. Yield per unit area of grain crops in Guangzhou, Guangdong, and China during the study period. Data were obtained from the Guangdong Rural Statistical Yearbook and the National Bureau of Statistics of China (http:/ / www.stats.gov.cn/, accessed on 5 January 2021).

Previous studies have found that the slope is closely related to CLQ; that is, the greater the slope, the worse the CLQ $[30,74]$. More than $70 \%$ of the cultivated land in Guangzhou is distributed in areas with slopes of $>5^{\circ}$, which seriously affects the CLQ in Guangzhou. Therefore, carrying out land leveling projects and ecological agricultural projects is highly recommended $[75,76]$.

The obstacle effect of the stable productivity capacity to CLQ in Guangzhou gradually increased, which was mainly because the cultivated land experienced severe natural disasters from 2010 to 2018 (Figure 10). Implementing conservation agriculture and strengthening crop management are effective measures for reducing the adverse impacts of natural disasters $[17,77]$. To ensure that cultivated land can be harvested after natural disasters, policymakers should continue to implement well-facilitated farmland construction and strengthen its maintenance and management after completion.

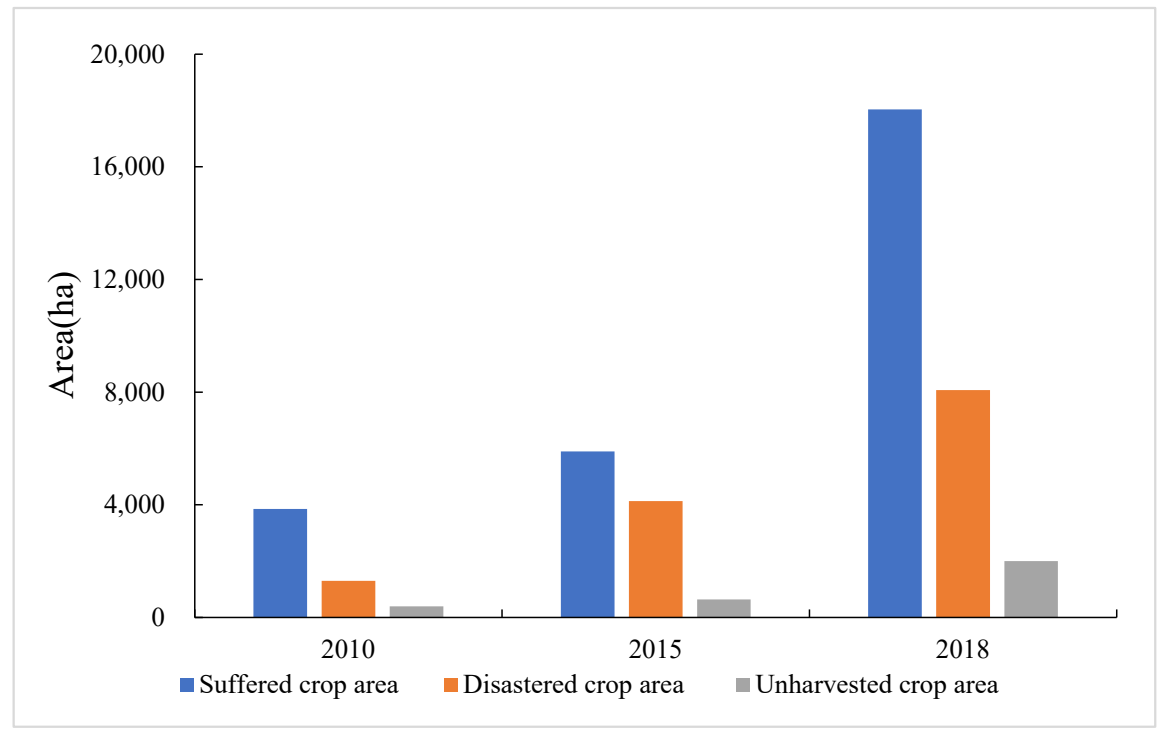

Figure 10. The crop areas that suffered from natural disasters in Guangzhou from 2010 to 2018. Data were obtained from the Guangdong Rural Statistical Yearbook (http: / www.stats.gov.cn/, accessed on 5 January 2021). 


\subsection{Limitations and Future Work}

Some potential reasons may lead to poor consistency between the remote sensing evaluation results and measured results of CLQ. First, inconsistent indicators lead to inconsistent results. In this study, the measured results were calculated based on thirteen field-measured indicators, while the remote sensing evaluation results were obtained from eight spatial attribute indicators, which may be the one reason for the inconsistency between the two results. Second, the remote sensing evaluation indicators of CLQ were more easily affected by factors such as crop varieties and climate (such as sun radiation and precipitations). In addition, one limitation of this study was that the spatial resolution of data was inconsistent. For example, the resolution of the NPP data was $500 \times 500 \mathrm{~m}$, that of the topsoil texture was $1 \times 1 \mathrm{~km}$, and that of the remaining data was $30 \times 30 \mathrm{~m}$. This can result in poor reliability of the evaluation results [10].

In the future, we will try our best to obtain indicators consistent with the measured data, so as to improve the accuracy of remote sensing evaluation of CLQ. The impact of crop varieties, land use and climate factors on the CLQ should be explored. Moreover, constructing a more comprehensive and representative evaluation indicator system is still the key of CLQ evaluation.

\section{Conclusions}

In this study, a new CLQ evaluation method was developed by integrating multisource remote sensing data to reveal the spatiotemporal patterns of the CLQ in Guangzhou from 2010 to 2018. The results showed that CLQ in Guangzhou continuously improved during the study period. The amount of high-quality cultivated land increased, while that of medium- and low-quality cultivated land decreased. CLQ in the eastern and northern parts of Guangzhou continuously improved, while that in the western and southern areas initially decreased and then improved. However, CLQ was low in the central region throughout the study period. Soil fertility size, high productivity capacity, and stable productivity capacity were the main obstacles for the improvement of CLQ in Guangzhou. Accordingly, we proposed a series of targeted measures, such as adopting reasonable crop rotation, strengthening crop management, and constructing well-facilitated farmland. The CLQ evaluation method proposed in this study is suitable for macro-regional scale research. The evaluation results provide clear guidance for further improvement of CLQ in Guangzhou.

Author Contributions: Conceptualization, D.D.; methodology, D.D. and J.S.; software, D.D. and S.L.; validation, D.D. and L.F.; formal analysis, H.C.; investigation, D.D., S.L. and X.S.; resources, D.D. and X.S.; data curation, F.Z. and L.X.; writing-original draft preparation, D.D.; writing-review and editing, D.D. and X.S.; visualization, W.Y.; supervision, X.S. and P.Y; project administration, X.S.; funding acquisition, P.Y. All authors have read and agreed to the published version of the manuscript.

Funding: This research was funded by the National Natural Science Foundation of China (grant no. U1901601, 41921001, and 41901227), the National Key Research and Development Program of China (grant no. 2019YFA0607401) and the Technology Innovation Center for Land Engineering and Human Settlements, Shaanxi Land Engineering Construction Group Co., Ltd. and Xi'an Jiaotong University (Grant No. 2021WHZ0072).

Institutional Review Board Statement: Not applicable.

Informed Consent Statement: Not applicable.

Data Availability Statement: Not applicable.

Acknowledgments: We thank the anonymous reviewers for the provided comments and suggestions that have helped us to improve the paper.

Conflicts of Interest: The authors declare no conflict of interest. 


\section{References}

1. Li, Y.; Chang, C.; Wang, Z.; Qi, G.; Dong, C.; Zhao, G. Upscaling remote sensing inversion model of wheat field cultivated land quality in the Huang-Huai-Hai agricultural region, China. Remote Sens. 2021, 13, 5095. [CrossRef]

2. Antón, J.; Cattaneo, A.; Kimura, S.; Lankoski, J. Agricultural risk management policies under climate uncertainty. Global Environ. Chang. 2010, 23, 1726-1736. [CrossRef]

3. Li, J.L.; Wu, W.J.; Ye, X.X.; Jiang, H.; Gan, R.J.; Wu, H.L.; He, J.L.; Jiang, Y.L. Innovative trend analysis of main agriculture natural hazards in China during 1989-2014. Nat. Hazards. 2019, 95, 677-720. [CrossRef]

4. Martínez-Mena, M.; Carrillo-López, E.; Boix-Fayos, C. Long-term effectiveness of sustainable land management practices to control runoff, soil erosion, and nutrient loss and the role of rainfall intensity in Mediterranean rainfed agroecosystems. Catena 2020, 187, 104352. [CrossRef]

5. Wolka, K.; Birhanu, B.; Vegard, M.; Jan, M. Soil and water conservation management on hill slopes in Southwest Ethiopia. I. Effects of soil bunds on surface runoff, erosion and loss of nutrients. Sci. Total Environ. 2021, 757, 142877. [CrossRef]

6. Raut, N.; Dörsch, P.; Sitaula, B.K.; Bakken, L.R. Soil acidification by intensified crop production in South Asia results in higher $\mathrm{N}_{2} \mathrm{O} /\left(\mathrm{N}_{2}+\mathrm{N}_{2} \mathrm{O}\right)$ product ratios of denitrification. Soil Biol. Biochem. 2012, 55, 104-112. [CrossRef]

7. Zhu, Q.C.; Liu, X.J.; Hao, T.X.; Zeng, M.F.; Shen, J.B.; Zhang, F.S.; De Vreies, W. Modeling soil acidification in typical Chinese cropping systems. Sci. Total Environ. 2018, 613-614, 1339-1348. [CrossRef]

8. Liu, S.J.; Wang, X.D.; Guo, G.L.; Yan, Z.G. Status and environmental management of soil mercury pollution in China: A review. J. Environ. Manag. 2021, 27, 111442. [CrossRef]

9. Prăvălie, R.; Patriche, C.; Borrelli, P. Arable lands under the pressure of multiple land degradation processes. A global perspective. Environ. Res. 2021, 194, 110697. [CrossRef]

10. Zhao, C.; Zhou, Y.; Jiang, J.H.; Xiao, P.N.; Wu, H. Spatial characteristics of cultivated land quality accounting for ecological environmental condition: A case study in hilly area of northern Hubei province, China. Sci. Total Environ. 2021, 774, 145765. [CrossRef]

11. Chen, Z.F.; Shi, D.M. Spatial structure characteristics of slope farmland quality in Plateau mountain area: A case study of Yunnan Province, China. Sustainability 2020, 12, 7230. [CrossRef]

12. Wang, L.; Zhou, Y.; Li, Q.; Xu, T.; Wu, Z.X.; Liu, J.Y. Application of three deep machine-learning algorithms in a construction assessment model of farmland quality at the county scale: Case study of Xiangzhou, Hubei Province, China. Agriculture 2021, 11, 72. [CrossRef]

13. Teng, Y.G.; Wu, J.; Lu, S.J.; Wang, Y.Y.; Jiao, X.D.; Song, L.T. Soil and soil environmental quality monitoring in China: A review. Environ. Int. 2014, 69, 177-199. [CrossRef] [PubMed]

14. Askari, M.S.; O'Rourke, S.M.; Holden, N.M. Evaluation of soil quality for agricultural production using visible-near-infrared spectroscopy. Geoderma 2015, 243-244, 80-91. [CrossRef]

15. Obade, V.P. Integrating management information with soil quality dynamics to monitor agricultural productivity. Sci. Total Environ. 2019, 651, 2036-2043. [CrossRef]

16. Dumanski, J.; Pieri, C. Land quality indicators: Research plan. Agric. Ecosyst. Environ. 2000, 81, 93-102. [CrossRef]

17. Danso, I.; Webber, H.; Bourgault, M. Crop management adaptations to improve and stabilize crop yields under low-yielding conditions in the Sudan Savanna of West Africa. Eur. J. Agron. 2018, 101, 1-9. [CrossRef]

18. Murray, F.; Germán, B.; Bernard, T.; Vigllzzo, E.F.; Jobbagy, E.G. Productive performance of alternative land covers along aridity gradients: Ecological, agronomic and economic perspectives. Agric. Syst. 2016, 149, 20-29. [CrossRef]

19. Song, W.; Wu, K.N.; Zhao, H.F.; Zhao, R.; Li, T. Arrangement of high-standard basic farmland construction based on village-region cultivated land quality uniformity. Chin. Geogr. Sci. 2019, 29, 325-340. [CrossRef]

20. Smith, A.; Snapp, S.; Dimes, J.; Gwenambira, C.; Chikowo, R. Doubled-up legume rotations improve soil fertility and maintain productivity under variable conditions in maize-based cropping systems in Malawi. Agric. Syst. 2016, 145, 139-149. [CrossRef]

21. Xu, W.Y.; Jin, J.X.; Jin, X.B.; Xiao, Y.Y.; Ren, J.; Liu, J.; Sun, R.; Zhou, Y.K. Analysis of changes and potential characteristics of cultivated land productivity based on MODIS EVI: A case study of Jiangsu Province, China. Remote Sens. 2019, $11,2041$. [CrossRef]

22. Zornoza, R.; Acosta, J.A.; Bastida, E.; Domínguez, S.G.; Toledo, D.M.; Faz, A. Identification of sensitive indicators to assess the interrelationship between soil quality, management practices and human health. Soils 2015, 1, 173-185. [CrossRef]

23. Zhou, Y.; Li, X.H.; Liu, Y.S. Cultivated land protection and rational use in China. Land Use Policy 2021, 106, 105454. [CrossRef]

24. Ministry of Agriculture and Rural Areas of People's Republic of China. NY/T1634-2008: Technical Regulations for Investigation and Quality Evaluation of Cultivated Land. 2008. Available online: https://www.antpedia.com/standard/5691996.html (accessed on 5 January 2021).

25. Ministry of Land and Resources of People's Republic of China. GB/T28407-2012: Rules for Quality Grading of Agricultural Land. 2012. Available online: https:/ / max.book118.com/html/2017/0703/119921593.shtm (accessed on 5 January 2021).

26. Ministry of Land and Resources of People's Republic of China. GB/T33469-2016: Cultivated Land Quality Grade. 2016. Available online: http:/ /nynct.jiangsu.gov.cn/art/2020/5/22/art_13477_9155231.html (accessed on 5 January 2021).

27. Lin, L.; Ye, Z.R.; Gan, M.Y. Quality perspective on the dynamic balance of cultivated land in Wenzhou, China. Sustainability 2017, 9, 95. [CrossRef] 
28. Chen, Y.; Zhu, M.K.; Lu, J.L.; Zhou, Q.; Ma, W.B. Evaluation of ecological city and analysis of obstacle factors under the background of high-quality development: Taking cities in the Yellow River Basin as examples. Ecol. Indic. 2020, $118,106771$. [CrossRef]

29. Mamehpour, N.; Rezapour, S.; Ghaemian, N. Quantitative assessment of soil quality indices for urban croplands in a calcareous semi-arid ecosystem. Geoderma 2021, 382, 114781. [CrossRef]

30. Peng, L.N.; Hu, Y.; Li, J.Y.; Du, Q.Y. An improved evaluation scheme for performing quality assessments of unconsolidated cultivated land. Sustainability 2017, 9, 1312. [CrossRef]

31. Shi, Y.Y.; Duan, W.K.; Fleskens, L.; Li, M.; Hao, J.M. Study on evaluation of regional cultivated land quality based on resourceasset-capital attributes and its spatial mechanism. Appl. Geogr. 2020, 125, 102284. [CrossRef]

32. Choudhury, B.U.; Mandal, S. Indexing soil properties through constructing minimum datasets for soil quality assessment of surface and profile soils of intermontane valley (Barak, North East India). Ecol. Indic. 2021, 123, 107369. [CrossRef]

33. Tan, Y.Z.; Chen, H.; Lian, K.; Yu, Z.N. Comprehensive evaluation of cultivated land quality at county scale: A case study of Shengzhou, Zhejiang Province, China. Int. J. Environ. Res. Public Health 2020, 17, 1169. [CrossRef]

34. Ma, J.N.; Zhang, C.; Yun, W.J.; Lv, Y.H.; Chen, W.L.; Zhu, D.H. The temporal analysis of regional cultivated land productivity with GPP based on 2000-2018 MODIS data. Sustainability 2020, 12, 411. [CrossRef]

35. Liu, Y.S.; Peng, Y.P.; Xia, Z.Q. Towards realistic assessment of cultivated land quality in an ecologically fragile environment: A satellite imagery-based approach. Appl. Geogr. 2010, 30, 271-281. [CrossRef]

36. Li, Z.; Lun, F.; Liu, M.; Xiao, X.; Wang, C.Y.; Xu, Y.Q.; Qi, W.; Sun, D.F. Rapid diagnosis of agricultural soil health: A novel soil health index based on natural soil productivity and human management. J. Environ. Manag. 2021, 277, 111402. [CrossRef] [PubMed]

37. Wang, Z.; Wang, L.M.; Xu, R.N.; Huang, H.T.; Wu, F. GIS and RS based assessment of cultivated land quality of Shandong Province. Procedia Environ. Sci. 2012, 12, 823-830. [CrossRef]

38. Omer, M.; Idowu, O.J.; Brungard, C.W.; Ulery, A.L.; Adedokun, B.; McMillan, N. Visible near-infrared reflectance and laserinduced breakdown spectroscopy for estimating soil quality in arid and semiarid agroecosystems. Soil Syst. 2020, 4, 42. [CrossRef]

39. Malerba, D. Poverty-energy-emissions pathways: Recent trends and future sustainable development goals. Energy Sustain. Dev. 2019, 49, 109-124. [CrossRef]

40. Qian, F.K.; Chi, Y.R.; Lal, R. Spatiotemporal characteristics analysis of multifunctional cultivated land: A case-study in Shenyang, Northeast China. Land Degrad Dev. 2020, 31, 1812-1822. [CrossRef]

41. National Bureau of Statistics of China. Available online: http://www.stats.gov.cn/ (accessed on 12 November 2020).

42. Chong, Z.H.; Pan, S. Understanding the structure and determinants of city network through intrafirm service relationships: The case of Guangdong-Hong Kong-Macao Greater Bay Area. Cities 2020, 103, 102738. [CrossRef]

43. Gong, J.Z.; Jiang, C.; Chen, W.L.; Chen, X.Y.; Liu, Y.S. Spatiotemporal dynamics in the cultivated and built-up land of Guangzhou: Insights from zoning. Habitat. Intern. 2018, 82, 104-112. [CrossRef]

44. Arshad, M.A.; Martin, S. Identifying critical limits for soil quality indexes in agroecosystems. Agric. Ecosyst. Environ. 2002, 88, 153-160. [CrossRef]

45. Drobnik, T.; Greiner, L.; Keller, A.; Grêt-Regamey, A. Soil quality indexes-from soil functions to ecosystem services. Ecol. Indic. 2018, 94, 151-169. [CrossRef]

46. Asante, B.O.; Omphile, T.; Kwabena, N.A.; VillanO, R.A. Evaluating productivity gaps in maize production across different agroecological zones in Ghana. Agric. Syst. 2019, 176, 102650. [CrossRef]

47. Turner, B.L.; Meyer, W.B. Land use and land cover in global environmental change: Considerations for study. Int. Soi. Sci. J. 1991, 130, 669-680. [CrossRef]

48. Wang, J.H.; Tao, P.F.; Yuan, Y.; Li, Z.Z.; Yang, J.J. PSR-based evaluation of the cultivated land quality in HaiLun city of Heilongjiang Province. Geology. Res. 2020, 29, 525-532. [CrossRef]

49. Zhu, M.B.; Liu, S.S.; Xia, Z.Q.; Wang, G.X.; Hu, Y.M.; Liu, Z.H. Crop growth stage GPP-driven spectral model for evaluation of cultivated land quality using GA-BPNN. Agriculture 2020, 10, 318. [CrossRef]

50. Scholten, T.; Goebes, P.; Kuhn, P. On the combined effect of soil fertility and topography on tree growth in subtropical forest ecosystems-a study from SE China. J. Plant Ecol. 2017, 10, 111-127. [CrossRef]

51. Yao, M.L.; Shao, D.G.; Lv, C.H.; An, R.H.; Gu, W.Q.; Zhou, C. Evaluation of arable land suitability based on the suitability function-A case study of the Qinghai-Tibet Plateau. Sci. Total Environ. 2021, 787, 147414. [CrossRef]

52. Fathizad, H.; Ardakania, M.A.H.; Heung, B.; Sodaiezadeh, H.; Rahmani, A.; Fathabadi, A.; Scholten, T.; Taghizadeh-Mehrjardi, R. Spatio-temporal dynamic of soil quality in the central Iranian desert modeled with machine learning and digital soil assessment techniques. Ecol. Indic. 2020, 118, 106736. [CrossRef]

53. Lai, Z.Q.; Chang, D.; Li, S.; Li, D. Optimizing land use systems of an agricultural watershed in China to meet ecological and economic requirements for future sustainability. Glob Ecol. Conserv. 2022, 33, e01975. [CrossRef]

54. He, C.Y.; Liu, Z.F.; Xu, M.; Ma, Q.; Dou, Y.Y. Urban expansion brought stress to food security in China: Evidence from decreased cropland net primary productivity. Sci. Total Environ. 2017, 576, 660-670. [CrossRef]

55. Imhoff, M.L.; Bounoua, L.; DeFries Ruth Lawrence, W.T.; Stutzer, D.; Tucker, C.J.; Ricketts, T. The consequences of urban land transformation on net primary productivity in the United States. Remote Sens Environ. 2004, 89, 434-443. [CrossRef] 
56. Kim, M.; Jang, Y.C.; Lee, S. Application of Delphi-AHP methods to select the priorities of WEEE for recycling in a waste management decision-making tool. J. Environ. Manag. 2013, 128, 941-948. [CrossRef] [PubMed]

57. Wang, X.Q.; Shi, W.J.; Sun, X.F.; Wang, M. Comprehensive benefits evaluation and its spatial simulation for well-facilitated farmland projects in the Huang-Huai-Hai Region of China. Land Degrad Dev. 2020, 31, 1837-1850. [CrossRef]

58. Jenks, G.F. The data model concept in statistical mapping. Int. Yearb. Cartogr. 1967, 7, 186-190.

59. Liu, J.Y.; Liu, M.L.; Tian, H.Q.; Zhuang, D.F.; Zhang, Z.X.; Zhang, W.; Tang, X.M.; Deng, X.Z. Spatial and temporal patterns of China's cropland during 1990-2000: An analysis based on Landsat TM data. Remote Sens Environ. 2005, 98, 442-456. [CrossRef]

60. Song, W.; Liu, M. Farmland conversion decreases regional and national land quality in China. Land Degrad Dev. 2017, 28, 459-471. [CrossRef]

61. Jiang, G.H.; Zhang, R.; Ma, W.; Zhou, D.Y.; Wang, X.P.; He, X. Cultivated land productivity potential improvement in land consolidation schemes in Shenyang, China: Assessment and policy implications. Land Use Policy 2017, 68, 80-88. [CrossRef]

62. Su, Y.; Qian, K.; Lin, L.; Wang, K.; Guan, T.; Gan, M.Y. Identifying the driving forces of non-grain production expansion in rural China and its implications for policies on cultivated land protection. Land Use Policy 2020, 92, 104435. [CrossRef]

63. Bucała-Hrabia, A. Long-term impact of socio-economic changes on agricultural land use in the Polish Carpathians. Land Use Policy. 2017, 64, 391-404. [CrossRef]

64. Mitter, H.; Techen, A.; Sinabell, F. Shared Socio-economic Pathways for European agriculture and food systems: The Eur-Agri-SSPs Global Environ. Chang. 2020, 65, 102159. [CrossRef]

65. Zhang, R.R.; Ma, W.M.; Liu, J.J. Impact of government subsidy on agricultural production and pollution: A game-theoretic approach. J. Clean Prod. 2021, 285, 124806. [CrossRef]

66. Ma, D.K.; Yin, L.N.; Ju, W.L.; Li, X.K.; Liu, X.X.; Deng, X.P.; Wang, S.W. Meta-analysis of green manure effects on soil properties and crop yield in northern China. Field Crop Res. 2021, 266, 108146. [CrossRef]

67. Hosseinzadeh, M.H.; Ghalavand, A.; Boojar, M.M.A.; Modarres-Sanavy, S.A.M.; Mokhtassi-Bidgoli, A. Application of manure and biofertilizer to improve soil properties and increase grain yield, essential oil and $\omega 3$ of purslane (Portulaca oleracea L.) under drought stress. Soil Till. Res. 2021, 205, 104633. [CrossRef]

68. Shen, D.D.; Li, G. Empirical research on the relation between agricultural technology progress and China's grain production-An analysis based on 31 provincial panel data from 2009 to 2015. J. Henan Univ. Eng. 2019, 34, 19-23. [CrossRef]

69. Liao, Q.; Hu, Y.M.; Hu, X.F.; Zhao, J.Y.; Wang, L. Spatial variability of topsoil nutrients in typical lateritic red soil areas of Guangdong province. Bull Soil. Water. Conserv. 2015, 35, 322-328. (In Chinese)

70. Kavitha, B.; Reddy, P.V.L.; Kim, B.; Lee, S.S.; Pandey, S.K.; Kim, K.H. Benefits and limitations of biochar amendment in agricultural soils: A review. J. Environ. Manag. 2018, 227, 146-154. [CrossRef]

71. Wang, H.D.; Wu, L.F.; Cheng, M.H.; Zhang, F.C.; Zou, Y.F.; Chau, H.W.; Gao, Z.J.; Wang, X.K. Coupling effects of water and fertilizer on yield, water and fertilizer use efficiency of drip-fertigated cotton in northern Xinjiang, China. Field Crop Res. 2018, 219, 169-179. [CrossRef]

72. Femeena, P.V.; Sudheer, K.P.; Cibin, R.; Chaubey, I. Spatial optimization of cropping pattern for sustainable food and biofuel production with minimal downstream pollution. J. Environ. Manag. 2018, 212, 198-209. [CrossRef]

73. Paudel, G.P.; Kc, D.B.; Rahut, D.B.; Justice, S.E.; McDonald, A.J. Scale-appropriate mechanization impacts on productivity among smallholders: Evidence from rice systems in the mid-hills of Nepal. Land Use Policy 2019, 85, 104-113. [CrossRef]

74. Fan, J.Q.; Wang, L.; Qin, J.X.; Zhang, F.R.; Xu, Y. Evaluating cultivated land stability during the growing season based on precipitation in the Horqin Sandy Land, China. J. Environ. Manag. 2020, 276, 111269. [CrossRef]

75. Liu, S.L.; Dong, Y.H.; Li, D.; Liu, Q.; Wang, J.; Zhang, X.L. Effects of different terrace protection measures in a sloping land consolidation project targeting soil erosion at the slope scale. Ecol. Eng. 2013, 53, 46-53. [CrossRef]

76. Guo, B.B.; Fan, Y.L.; Jin, X.B.; Zhou, Y.K. Monitoring the effects of land consolidation on the ecological environmental quality based on remote sensing: A case study of Chaohu Lake Basin, China. Land Use Policy 2020, 95, 104569. [CrossRef]

77. Rusinamhodzi, L.; Corbeels, M.; van Wijk, M.T.; Rufino, M.C.; Nyamangara, J.; Giller, K.E. A meta-analysis of long-term effects of conservation agriculture on maize grain yield under rain-fed conditions. Agron. Sustain. Dev. 2011, 31, 657-673. [CrossRef] 